\title{
Patients' Insurance Status Influences the Clinical Management of Their Thyroid Cancer
}

\section{Douglas Van Nostrand}

\begin{abstract}
Division of Nuclear Medicine, Georgetown University School of Medicine, Medstar Washington Hospital Center, Washington, District of Columbia, U.S.A.
\end{abstract}

Review of: Ullmann TM, Gray KD, Limberg J, Stefanova D, Moore MD, Buicko J, Finnerty B, Zarnegar R, Fahey TJ, Beninato TJ 2019 Insurance status is associated with extent of treatment for patients with papillary thyroid carcinoma. Thyroid, 14 October 2019 https://www.liebertpub.com/doi/pdf/10.1089/ thy.2019.0245 [Epub ahead of print]

\section{SUMMARY}

\section{Background}

Ullman et al. have published an article evaluating the potential association of a patient's insurance status to the patient's clinical management of papillary thyroid carcinoma (PTC) (1). They hypothesized that patients with insurance coverage who had differentiated thyroid cancer would have lower-risk tumors at the time of diagnosis, and they would also be much more likely to receive adjuvant therapies, compared to those without insurance plans.

\section{Methods}

From the American College of Surgeons' National Cancer Database, Ullman et al. identified patients who had > 2 mm PTC between 2004 and 2015.
These patients were subdivided into those who had no insurance and those who had private insurance. The frequency of risk factors at the time of diagnosis was tabulated amongst groups. Multiple factors were analyzed as predictors for which group was more likely to receive extended treatment.

\section{Results}

Of 190,298 patients identified, 139,675 (73\%) had private insurance and 50,623 (27\%) had no insurance. The subject demographics are summarized in Table 1. Private insurance vs no insurance was an independent predictor for treatment with thyroidectomy, lymphadenectomy, and adjuvant I-131 adjuvant therapy. However, patients with

\section{Table 1: Association of Insurance and Risk Factors}

\begin{tabular}{|l|c|c|c|c|c|}
\hline & $\begin{array}{c}\text { Uninsured } \\
\text { Patients }\end{array}$ & $\begin{array}{c}\text { Privately Insured } \\
\text { Patients }\end{array}$ & Medicaid & Medicare & P \\
\hline $\begin{array}{l}\text { Extrathyroidal } \\
\text { Extension }\end{array}$ & $25 \%$ & $19 \%$ & $23 \%$ & $26 \%$ & $<0.001$ \\
\hline $\begin{array}{l}\text { Lympho-Vascular } \\
\text { Invasion }\end{array}$ & $26 \%$ & $12 \%$ & $15 \%$ & $12 \%$ & $<0.001$ \\
\hline Positive Margins & $16 \%$ & $12 \%$ & $14 \%$ & $16 \%$ & $<0.001$ \\
\hline Distant Mets & $1.2 \%$ & $0.6 \%$ & $1.1 \%$ & $1.9 \%$ & $<0.001$ \\
\hline
\end{tabular}




\section{THYROID CANCER Patients' Insurance Status Influences the Clinical Management of Their Thyroid Cancer}

Douglas Van Nostrand

Medicare or Medicaid ". . . were no more likely to receive these treatments than uninsured patients."

\section{Conclusions}

This article demonstrates that patient with private insurance had less aggressive disease at the time of diagnosis, and these patients were also more likely to be treated with thyroidectomy, lymphadenectomy, and I-131 therapy when compared to patients who were uninsured.

\section{COMMENTARY}

The results of Ullman et. al's article are not surprising: those with insurance have less aggressive PTC at diagnosis and are more likely to be treated with total thyroidectomy, lymphadenectomy, and I-131 compared to those without private insurance. However, this study raises multiple clinical, ethical, and societal questions.

First, what are the factors at work behind the alteration of patient care based on private insurance or no insurance? The authors address this issue in their discussion, identify multiple potential factors, and conclude that probably all the factors, as well as others, are at work.

Second, what does this information in this report potentially imply clinically regarding the patient's care? Although one may speculate that any grouping of patients whatsoever would have some patients that are over treated and some that are undertreated, the reported data indicate that potentially more patients with private insurance may be over treated and more patients with no insurance may be undertreated.

But then this begs the third and most important question of how do we try to manage the many different factors that are resulting in over and under treatment? Do we 1) encourage those patients who cannot afford health insurance to obtain health insurance but then they may be over treated, 2) require those patients who cannot afford health insurance to have health insurance, and if they do not, impose a penalty, 3) offer basic health care from the state or federal government for those who cannot afford such, and if so, how do we determine if they cannot afford health insurance, 4) implement universal health care for all, which is a strong position of many democratic presidential candidates' and their supporters' position, and on and on?

It is this commentator's viewpoint that anyone who thinks that they have the definitive solution is wrong. Every option listed or not listed here has additional sets of new problems and quagmires from 1) implementation, 2) how is it paid for, 3) who establishes what should or should not be done? Just in regard to the latter problem, even the most knowledgeable, experienced, and published researchers and clinicians involved in the management of papillary thyroid carcinoma cannot agree on what should be the proper treatment for papillary thyroid cancer.

Meanwhile, we are moving more and more to "individualized" and "personalized" medicine with the additional consideration of the desires' of the patients and whether a particular patient is a minimalist or maximalist (2). In conclusion, the authors have stated wisely that the practicing physician must consider the "disparities" of treatment when implementing "appropriate" treatments, referrals, and follow up of insured and under insured patients. But for me, that is not the issue. Health care and insurance are as complex as the issue of life itself, and we should not have any illusions that it is an issue of insurance vs no insurance. 

Clinical Management of Their Thyroid Cancer

Douglas Van Nostrand

\section{References}

1. Ullmann TM, Gray KD, Limberg J, Stefanova D, Moore MD, Buicko J, Finnerty B, Zarnegar R, Fahey TJ, Beninato TJ 2019 Insurance Status Is Associated with Extent of Treatment for Patients with Papillary Thyroid Carcinoma. Thyroid, 14 October 2019 https://www.liebertpub.com/doi/pdf/10.1089/ thy.2019.0245 [Epub ahead of print]
2. Groopman J, Hartzband P (eds). Your Medical Mind: How to Decide What is Right for You. New York. 2011. 